\title{
Motivation States among STEM and Non-STEM Undergraduates
}

\author{
David Palmer \\ School of Education, University of Newcastle, New South Wales, Australia \\ Email: david.palmer@newcastle.edu.au
}

\begin{abstract}
Student motivation influences retention in university STEM programs, but whereas most studies have focused on trait-like motivational factors relatively few have focused on motivation states (i.e., episodic experiences of being motivated to learn). The aim of this study was to investigate the states of motivation experienced by undergraduates in authentic lecture settings. Interviews were carried out with 43 university students from STEM and non-STEM specializations. Each interview was held immediately after a regular lecture, and the questions focused on the motivation states (defined as an active feeling of wanting to learn) that they experienced towards the end of the lecture, just before they were interviewed. Validity was established by triangulation of their interview responses. It was found that the motivation states of STEM students were significantly more negative than those of the non-STEM students. This was educationally important because it correlated overall with levels of concentration, although it was noted that some female STEM students managed to self-regulate their concentration. It was concluded that STEM students may be more susceptible to low motivation for learning during formal lectures.
\end{abstract}

Keywords: motivation state, concentration, self-regulation

\section{Introduction}

In recent years, there has been increasing interest in studying the motivation of STEM students during their undergraduate studies. This has largely been driven by concerns about the disparity between the increasing number of jobs that require STEM skills and the relative shortage of students who are completing STEM programs at university (Bayer Corporation, 2014; Byars-Winston, 2014). For example, roughly half the students who enroll in STEM disciplines drop out before finishing (Chen \& Soldner, 2013), and women can be particularly vulnerable to attrition from STEM (Thoman, Arizaga, Smith, Story, \& Soncuya, 2014).

Several motivation-related factors have been found to influence undergraduate STEM achievement and retention. These include self-efficacy (belief in one's ability to complete a task), individual interest in STEM (a long-term disposition to engage with STEM content), and achievement goals (reasons why students engage; Cromley, Perez, \& Kaplan, 2015; Perez, Cromley, \& Kaplan, 2014; Simon, Aulls, Dedic, Hubbard, \& Hall, 2015).

One commonality among these previous studies is that they have focused on trait-like constructs such as self-efficacy beliefs and long-term interests, and these are relatively stable, at least within particular contexts. Yet each of these does not necessarily predict the state of motivation (i.e., the active feeling of being motivated to learn) that students might experience in a particular learning episode at a particular time. This difference between state and trait is important, because it is in the positive state of motivation that new learning occurs: Winne and Marx (1989) stated that "a positive state of motivation is a necessary condition for students to learn from instruction" (p. 225).

Thus, if we are to develop a balanced understanding of student motivation in STEM then it is necessary to study not only traits but also states. The present study is designed to compare the states of motivation that STEM and non-STEM students experience in authentic settings. 


\section{Literature Review: Motivation States}

States of mind can be conceptualized as episodic experiences in which a particular feeling tends to dominate one's consciousness. Our knowledge of motivation states has been informed by studies of phenomena such as emotions (Turner \& Patrick, 2008), flow (Culbertson et al., 2015), situational interest (Renninger \& Hidi, 2016), and curiosity (Grossnickle, 2016). In classroom settings, states can sometimes fluctuate over relatively short periods of time in response to changes in topics or activities during a lesson (Vollmeyer \& Rheinberg, 2006). However, they can also persist unchanged throughout a lesson if the pedagogy continues to support sustained interest and attention (Ainley, 2006; Kim \& Schallert, 2014).

Schiefele (1999) argued that the main characteristic of the motivation state is a desire to immediately engage. Similarly, Wolters (2003) reported that the state of motivation is "a student's willingness to engage in and persist at a task" (p. 190); and Miele and Scholer (2018) defined the state of motivation as "the experience of being motivated to engage in a task" (p. 5). In educational settings, the state of motivation to learn has been described as an impulse to immediately engage in learning (Ainley, 2006; Grossnickle, 2016). This view has been adopted in studies carried out in some STEM-related studies: Rotgans and Schmidt (2017) for example, used the item "I want to know more about this topic" (p. 177) to identify the state of situational interest in a science lesson, and Randler and Bogner (2007) used the item "I would like to know more about this topic" to identify interest states when students worked on science problems. Miele and Scholer (2018) warned that the motivation state is not always positively valenced however, because when students are fatigued or bored they may experience a negative feeling of wanting to disengage.

Motivation states are thought to be very closely linked to levels of concentration and attention. According to Vollmeyer and Rheinberg (2006), the level of focused attention as students work on the learning material is a direct effect of the motivation state experienced at that time. Other authors have reported that high levels of concentration and attention seem to occur concurrently with positive motivation states such as flow (Culbertson et al., 2015), situational interest (Renninger \& Hidi, 2016), and state curiosity (Grossnickle, 2016). Studies in STEM-related fields have reported similar findings: Focused attention has been used as a behavioral indicator of the state of situational interest in science (Loukomies, Juuti, \& Lavonen, 2015) and engineering (Dohn, 2013). This is an important point from an educational perspective, because concentration and attention are essential behaviors of learning, since one cannot learn the material if one is not paying attention to it (Anderman, Noar, Zimmerman, \& Donohew, 2004).

A number of authors have investigated the factors that could influence the formation of motivation states. Winne and Marx (1989) argued that motivation states would arise from cognitive operations that combine the effects of pre-existing beliefs and dispositions, such as efficacy beliefs and attitudes, with information about the current task. Similarly, Schiefele (1999) and Miele and Scholer (2018) have argued that relatively stable motivational characteristics such as attributions, self-efficacy beliefs, expectancies, and task value beliefs are the immediate precursors of the motivation state. Contextual factors can also influence motivation states. For example, it has been found that pedagogical variables such as novelty and humor, can influence states of interest and curiosity (Grossnickle, 2016; Rotgans \& Schmidt, 2017; Tsai, Kunter, Lüdtke, Trautwein, \& Ryan, 2008); and Menna-Barreto and Wey (2008) found that fatigue can also influence the way students approach classroom tasks. Finally, research in STEM-related fields has indicated that the tempo of instruction may influence the state of flow state experienced by science students (Gyllenpalm, 2018). In addition, long-term individual interest can influence the state of situational interest in mathematics (Vainikainen, Salmi, \& Thuneberg, 2015); and autonomy and social involvement can influence situational interest in engineering activities (Dohn, 2013). Thus a wide variety of factors can potentially influence motivation states: Ainley (2006) stated that "Students come to the task with a range of goals and it is through interaction of these goals with task demands that specific on-task feeling states are triggered" (pp. 397-398).

The dynamic nature of motivation states presents methodological challenges for researchers. Loukomies, Juuti, and Lavonen (2015) found that observation of student facial expressions and behavior was not a reliable indicator of students' own evaluations of interest during a science lesson. On the other hand, asking the students to provide data during the lesson itself means that the learning activity needs 
to be interrupted, thus interfering with the students' attention and disrupting the natural formation of their motivation states. In addition, it is ethically not acceptable to interfere with students' learning during regular lessons, since their achievement may be negatively affected. Yet, it has also been noted that the possibility of memory bias is increased if data collection is delayed too long after the lesson (Loukomies, Juuti, \& Lavonen, 2015). One approach that might address all these problems would be to collect data from students immediately at the end of a regular lesson, and focus on the motivation states they experienced late in that lesson. In this way, the data collection would not interfere with the motivation state, and the time lag between the two would be relatively brief. This approach was adopted for the present study.

\section{The Present Study}

There does not appear to have been any previous study that has directly compared motivation states experienced by STEM and non-STEM students during regular undergraduate lectures. Yet it is important to do so, because if we are to have a balanced understanding of the motivation of STEM students, it should include all aspects of their motivation - their states as well as their traits. The aim of this study was to investigate the question,

Do STEM students differ from non-STEM students in the motivation states they experience in regular lectures?

\section{Method}

The study used a comparative design in authentic field settings. Data were collected by semi-structured interviews held immediately after regular lectures. A relatively large number of interviewees (43) was used in order to allow quantitative comparison between groups. In this way, the study used a combination of quantitative and qualitative techniques.

\subsection{Participants and Recruitment}

The participants were undergraduate students at a university in south-eastern Australia. Recruitment occurred in the following way. The interviewer personally attended regular lectures in a wide range of courses (details below), then at the end of each session, as the students were preparing to leave, he made a request to the full group asking that if any student was willing to be interviewed about "motivation" he/she should make contact there and then. When a student did volunteer, the interview was carried out immediately just outside the lecture theatre (only one interview was carried out on each occasion). The rationale for this approach was that as recruitment and data collection occurred at the end of the lecture there was minimal interference with each student's motivation state(s) during the lecture. In this way, the lecture itself remained an authentic educational experience that was not potentially corrupted by interruptions.

Most participants were in the 18-30-years age group. The STEM students comprised $56 \%$ of the participants. This group included students from a human bioscience course (38\% of this group), a mathematics course (33\% of this group), and a chemistry course (21\%), while an engineering course provided two participants $(8 \%)$. The non-STEM sample (44\% of participants) was more evenly balanced, with roughly equal representation from courses in sociology, visual arts, education, speech pathology, and accounting. In this way, the participants were a quasi-random sample (Kim \& Schallert, 2014) of students from a range of STEM and non-STEM courses. Overall, there were more males $(67 \%$ in the STEM group and $58 \%$ in the non-STEM group) than females, as these were the proportions who volunteered to participate.

The following is a brief description of the content of the courses. The human bioscience course covered structure and function in systems of the human body. The mathematics course covered linear algebra, calculus, and differential equations. The chemistry course covered atomic and molecular structure, and the engineering course covered mechanical engineering and design. The sociology course covered social and cultural issues in modern society. The visual arts course covered the theoretical analysis of visual art. The education course was an introduction to educational studies and the profession of teaching. The 
speech pathology course covered the identification of language disorders in children, and the accounting course covered fundamental principles of accrual accounting.

Since the participants self-selected for this study, it raised the issue of whether they were more motivated than other students. However, as will be shown in the results, many participants reported neutral or negative levels of motivation.

\subsection{The Interview Protocol, Validity, and Reliability}

Each interview lasted about 15 minutes. The interview questions focused on the motivation states that students had experienced later in the lecture (i.e., in the latter part of the lecture while content was still being presented). The same interviewer was used on each occasion. The interview guide questions were as follows.

Question 1. Students were shown the Scale Line (Figure 1) and were asked, "Later in that lecture, while the instructor was still presenting, did you experience a feeling of wanting to learn or not wanting to learn? If so, please mark it on the line."

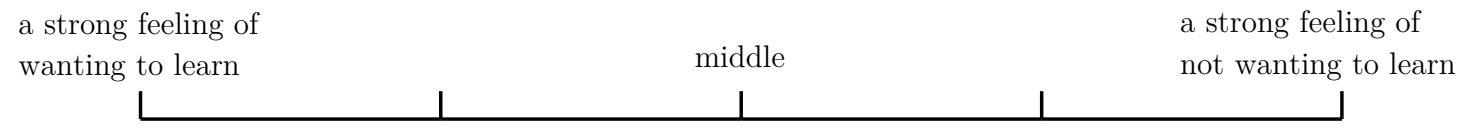

Figure 1. The scale line

Question 2. "Please describe that feeling."

Question 3. "How well were you concentrating at that time?" This question was included to help triangulate the motivation state, since highly positive motivation states should be accompanied by high concentration.

Question 4. "What factors contributed to your feeling of wanting to learn (or not wanting to learn)?"

Triangulation is a well-established method for ensuring validity and reliability (Golafshani, 2003). According to Long and Johnson (2000), validity and reliability can be established using data from a single interview, by triangulating the extent to which the interviewee's answers on a given topic are concordant and/or by asking the same question in different ways during the interview. The idea of reliability (i.e., replicability from one occasion to another) is considered questionable when the focus is on a particular event, as student experiences may vary from one event to another. For the purposes of the present study, it was therefore more important to establish validity. Construct validity for the motivation state was triangulated using (1) students' measurements of the feeling of wanting to learn (Interview Question 1), (2) students' verbal descriptions of that feeling (Interview Question 2); and (3) whether this feeling was linked to levels of concentration/attention (Interview Question 3).

\subsection{Data Analysis}

Quantitative analyses used measurements of the positions of the students' marks on the Scale Line (Figure 1). The position of the mark in millimetres was measured from the right hand end of the line, so the maximum score was 100 and the minimum score was zero. Other quantitative analyses used numerical scores that were coded for different response categories as explained in the results. A significance level of.05 was used for the statistical tests.

Qualitative techniques were based on inductive thematic analysis of the participants' verbal responses (Braun \& Clarke, 2006), whereby response segments that seemed to express the same idea were coded together. To check the reliability of the process, two coders independently categorized 36 response segments, and agreement was found to be $89 \%$. 


\section{$5 \quad$ Results}

\subsection{Levels of Wanting to Learn}

After measurement of the position of each student's mark on the Scale Line (Question 1) the means and standard deviations (SD) were found to be 46.79 (29.36) for STEM, and 64.47 (31.12) for non-STEM. A t-test for independent means was used to compare the two groups, and a significant difference with a moderate effect size was found, $t(43)=1.911, p=.0316, d=.5844$. This indicated that the motivation states experienced by the STEM students were significantly more negative than those experienced by the non-STEM students.

Responses to Question 2 were coded as either positive (i.e., indicating a feeling of wanting to learn), negative (a feeling of not wanting to learn), or neutral (no particular feeling either way). Examples of positive statements included, "As soon as she started talking about the differential equations I was right there, because I really wanted to know it" (male, mathematics) and "I just wanted to know more about it. Learn more about it" (female, visual arts). Negative responses included statements such as, "I didn't really want to learn that stuff right now" (female, education) and "I didn't like that style of example and I just had this automatic feeling of 'I don't want to learn that'" (male, mathematics). Neutral responses expressed either indifference ("In the middle. It's more like indifference. It's like 'I'm here", male, human bioscience) or a balance between wanting to learn and not wanting to learn ("I lost interest. I wouldn't say not wanting to learn, but feeling less strongly about wanting to learn it" male, accounting). Positive responses were coded for $38 \%$ of STEM and $61 \%$ of non-STEM, whereas $38 \%$ of STEM and $17 \%$ of non-STEM were coded as negative, and $24 \%$ of STEM and $22 \%$ of non-STEM were coded as neutral.

It is worth noting that the students with negative levels of wanting to learn typically indicated they did intend to learn the material at a later time at home (e.g., "That was me, just drained and no longer focusing on what was being said... I just wanted to go home and do it by myself later"; female, chemistry).

The first step in the process of triangulation was to check concurrence between the students' verbal responses (Question 2) and their marks on the Scale Line (Question 1). Each verbal response was assigned a score of either 1 (negative), 2 (neutral), or 3 (positive) and these were compared to the Scale Line measurements using a correlation test. A strong, positive correlation was found, $\mathrm{r}=.8186, \mathrm{n}=43$, $\mathrm{p}<.001$, indicating good agreement between the two data sources: scores above 50 on the Scale Line went with positive verbal descriptions, middle scores (around 50) went with neutral verbal descriptions, and scores less than 50 went with negative verbal descriptions. This suggested that the motivation state could be valenced from positive, through neutral, to negative.

\subsection{Levels of Concentration}

Students' statements about their levels of concentration (Question 3) were scored as either 1 (low; e.g., "I just switched off. I could hear her voice as background noise" male, human bioscience), 2 (moderate; e.g., "Partially. I would listen to it. I'd think about it, but then my mind would wander" female, human bioscience), or 3 (high; e.g., "Yes, well. I was visualizing the things he was talking about" male, engineering). For the purposes of triangulation, a correlation test was used to establish whether these levels of concentration were related to students' scores on the Scale Line (Question 1). A moderate, positive correlation was found, $r=.6536, n=39, p<.001$. This indicated that highly positive motivation states were usually accompanied by high levels of concentration, but neutral or negative motivation states were usually indicative of lower concentration.

In order to identify gender effects in STEM and non-STEM groups, further correlation tests were used to compare levels of concentration (Question 3) with scores on the Scale Line (Question 1). Strong, positive correlations were found for male non-STEM, $r=.8813, n=9, p=.002$, and female non-STEM students, $r=.9301, n=7, p=.002$. A moderately positive correlation was found for male STEM students, $r=.5788, n=16, p<.0188$, but there was no significant correlation for female STEM students $r=.115, n=7, p=.8061$. This suggested that female STEM students may have differed to the other 
groups in that their concentration was not as closely tied to their motivation state. A possible explanation for this is presented in the Discussion.

\subsection{Factors that Affected the Motivation State}

In Question 4, students had been asked to identify factors that had contributed to their motivation state. The results are shown in Figure 2. The category of "topic" was coded when students made comments about whether the information being presented was relevant, good, interesting, or valuable (e.g., "She was giving information that was not something we necessarily need to know towards our studies... I wasn't interested in learning that right now"; female, speech pathology). The category of "fatigue" was coded when students referred to tiredness, discomfort, or information overload (e.g., "I started getting tired as my mind got filled up with more things... You still want to understand it but you're losing motivation at the time"; male, mathematics). The category of "comprehension" included the extent to which students understood the information ("When something I didn't understand came along, that's when it dropped"; male, mathematics). Minor categories included "distraction" (when students stated it was because they felt distracted), "pedagogy" (when the instructor's delivery style had been a factor), "feedback" (when the instructor had asked questions and provided praise for answers), and "IT problems" (when malfunctions with equipment had interrupted the presentation).

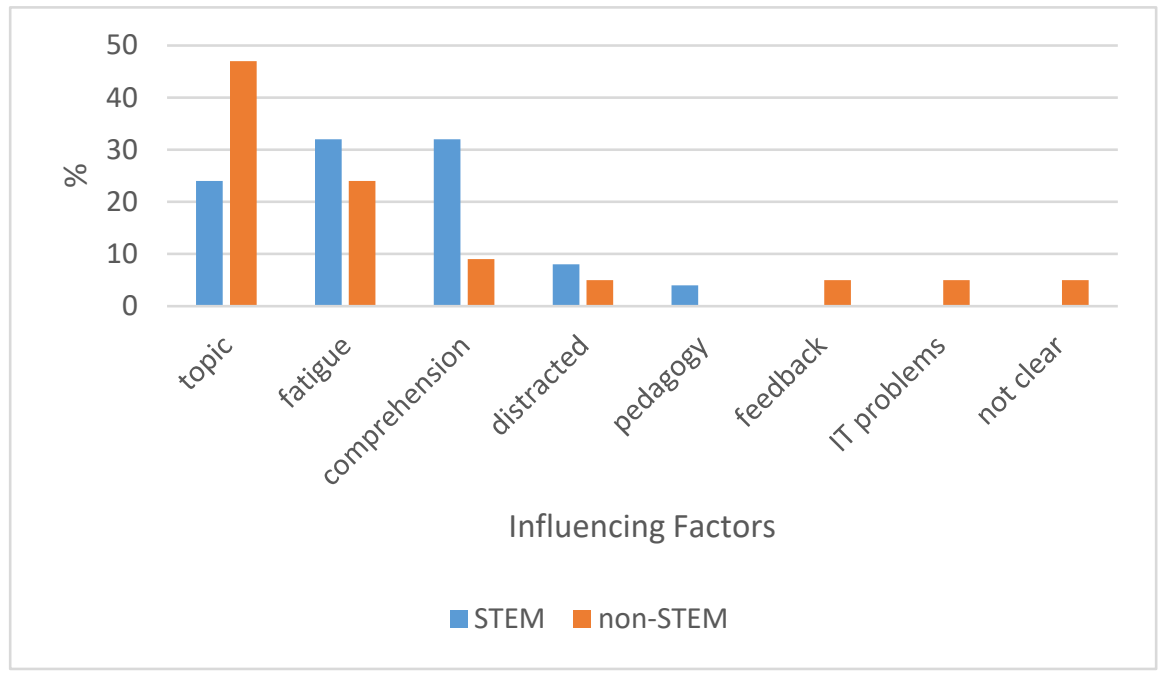

Figure 2. Factors influencing the motivation state for STEM $(n=24)$ and non-STEM $(n=19)$ students

As shown in Figure 2, the main factors for STEM students were topic, fatigue, and comprehension, whereas the main factors for non-STEM students were topic and fatigue. Chi-square tests were used to compare STEM and non-STEM students with regard to the topic category and comprehension category, since these appeared to show the most difference. However, no significant differences were found for either topic, $\mathrm{X}^{2}(2, \mathrm{~N}=46)=3.3889, p>.05$, or comprehension, $\mathrm{X}^{2}(2, \mathrm{~N}=46)=2.8067, p>.05$.

\section{Discussion}

This study aimed to compare the motivation states experienced by STEM and non-STEM undergraduates. The motivation state for learning was defined as an active feeling of wanting to learn the material being presented. This was triangulated by comparing measurements of students' marks on the Scale Line (Question 1) with their verbal descriptions of the feeling (Question 2), and with their reported levels of concentration at the time (Question 3). Moderate to strong correlations implied an acceptable degree of concurrence between the three types of data. This evidence suggests there was a valid identification of the motivation state. 


\subsection{Characteristics of the Motivation State}

One of the main findings was that the motivation state was valenced (Interview Questions 1 and 2). The positive dimension was an active feeling of wanting to learn, which varied in intensity from highly positive to moderately positive. The negative dimension was an active feeling of not wanting to learn, which also varied in intensity. Miele and Scholer (2018) suggested that the motivation state could become negatively valenced on occasion, but the present study has suggested that a neutral motivation state could also be experienced. The neutral zone was represented by an absence of any particular feeling about learning, so students reported they were just going through the motions of taking notes during the lecture. A feeling of indifference appeared to be the dominant feature of this state. The positive, neutral, and negative valences were educationally significant because they were positively correlated with levels of concentration (Question 3).

It is important to note that the negative motivation state did not represent an ongoing predisposition to avoid learning. Although some students experienced an active feeling of not wanting to learn during the lecture, their comments indicated that they did intend to learn the content at a later time at home. These findings emphasized the important difference between traits and states: Although much of the research on STEM motivation has centered on the former (e.g., Cromley, Perez, \& Kaplan, 2015; Perez, Cromley, \& Kaplan, 2014; Simon, Aulls, Dedic, Hubbard, \& Hall, 2015) the role played by the latter (states) should not be ignored. For example, a STEM student might have an ongoing goal to learn and achieve in a chemistry unit, but there might be particular occasions during that unit in which factors such as fatigue might create a temporary feeling of not wanting to learn. This episodic state of mind would not represent his/her normal disposition toward learning in STEM, but if it occurred regularly throughout the unit then its educational impact could be significant. In this way, the neutral and negative valences should not be interpreted as representing ongoing predispositions.

An important finding was that the motivation state was correlated with levels of concentration. The positive dimension of wanting to learn went with high levels of concentration, but if levels of wanting to learn were at neutral or negative levels then concentration was proportionally lower (Question 3). Unexpectedly, this correlation was only moderately positive rather than highly positive. This moderate level of correlation was surprising because previous authors (Winne \& Marx, 1989) have proposed that the state of motivation directly determines attention and concentration, implying there should be a 1:1 correlation. A possible explanation for this anomaly is that some of the students (particularly female STEM students, as discussed below) may have been self-regulating their concentration when their motivation state was neutral or negative. Self-regulation occurs when students make efforts to strategically control their cognitive processes (e.g., Järvenoja et al., 2017). Student comments such as "My mind was wandering... and I was thinking 'No. Get back on task. You have got to learn this stuff or you're going to fail"' (female, human bioscience) suggested that some students were using self-talk to regulate their concentration when the motivation state was neutral or negative. These instances of selfregulation may have weakened the correlation between the motivation state and the level of concentration. Thus, the results have suggested that the level of concentration can be a function of the motivation state and/or the ability to self-regulate.

Previous authors have suggested that relatively stable motivational characteristics such as attributions, self-efficacy beliefs, and individual interests are the main precursors of the motivation state (e.g., Miele \& Scholer, 2018), yet others have reported that episodic and situational factors such as fatigue and pedagogy can be influential (Menna-Barreto \& Wey, 2008; Gyllenpalm 2018). The results of the present study, suggested that both perspectives were valid, since responses to Question 4 suggested that the main factors influencing the motivation state included students' interest and value in the topic as well as episodic factors such as fatigue and discomfort, comprehension, pedagogy, and IT problems (Question 4). Interestingly, some students indicated that factors such as fatigue and discomfort might be less influential at home, where they had access to an online recording of the lecture:

I just thought I'll go home and have a rest and maybe one other day I'll study it. It's a lot easier when you're in your own comfort zone at home. Go to the fridge and you can go at your own pace, because with the lecture recording you can pause and then start again. (male, human bioscience). 


\subsection{Differences between STEM and Non-STEM Students}

The main purpose of the study was to investigate whether STEM students differed from non-STEM students regarding their motivation states. Two significant differences were found. First, responses to Question 1 revealed that the motivation states experienced by the non-STEM students were significantly more positive than those experienced by the STEM students. In fact, the mean for STEM students was into the negative range (46.79) whereas the mean for non-STEM students was moderately positive (64.47). This was an unexpected finding because, at university level, students have the freedom to choose courses that align with their interests (Maltese, Melki, \& Wiebke, 2014) so one would expect most students to be highly positive about learning the content. However, students in both groups stated that fatigue had been one of the main factors that had affected their motivation state (Question 4). In many cases this was cognitive fatigue that had been caused by the rapid presentation of too much content: "When you get pumped up with so much information that you just switch off. When there's so much stuff to learn and you just switch off" (male, human bioscience); and "My brain started getting a little bit tired... because there was new information pushing the boundaries of the learning" (male, accounting). It has long been known that the rate of information processing during science learning, as well as the cognitive demand and the ability of the learner to retain information in short-term memory, are fundamental considerations for science content learning (Anderson, 1983; Tekkumru-Kisa, Stein, \& Schunn, 2015), and the perceived difficulty of STEM courses in comparison to non-STEM has been welldocumented (Rizvi, 2015; Whalen \& Shelley, 2010). The results of the present study would suggest that when students experience cognitive overload during lectures, it negatively impacts their motivation state, and this has a flow on effect by lowering their level of concentration. In this way, a negative spiral is formed.

The second difference between STEM and non-STEM was that the female STEM students were the only group in which their motivation state was not correlated with their level of concentration (Question 3). One explanation for this is that some of the female STEM students reported that they made efforts to force themselves to concentrate despite their neutral or negative motivation states. They achieved this mainly through self-talk: "I kept telling myself to tune back in. I was forcing myself" (female, human bioscience). Thus, this willingness to force themselves to concentrate may have nullified the relationship between the motivation state and the level of concentration. This finding has parallels with previous studies that have found that female students show higher levels of self-regulation (Wolters \& Pintrich, 1998) and that females in STEM disciplines believe they will need to apply greater effort in order to overcome the disadvantages of negative stereotypes and gender bias (Smith, Lewis, Hawthorne, \& Hodges, 2013). The ability to maintain concentration despite neutral or negative feelings about learning is a positive attribute for a student, so perhaps other students might have something to learn from these female STEM students.

\section{Conclusions, Limitations, and Implications}

In order to identify the factors that might affect the persistence of young men and women in STEM programs at university, it is not only necessary to understand the trait-like factors that influence their motivation, but also the states of motivation that they experience during their lectures. The students in this study did experience a motivation state that was valenced from positive (an active feeling of wanting to learn), through neutral (a feeling of indifference about learning), to negative (an active feeling of not wanting to learn). These states were educationally significant because they positively correlated with levels of concentration.

A significant problem for many STEM students was that their motivation state was in the neutral or negative range, late in the lecture. These low levels were most often the result of cognitive fatigue. The students with negative motivation states reported that, although they did not want to learn at that time, they did intend to learn the material at home at a later time. On the other hand, some of the female STEM students displayed a positive attribute in comparison to other students because they managed to self-regulate their concentration, so although they had experienced neutral or negative motivation states, they reported using self-talk to force themselves to remain focused.

There were two limitations to this study. First, the participants were university students who typically have freedom to choose courses that match their dispositions, so it should not be assumed that 
elementary or secondary students in compulsory education would experience the same patterns of motivation. Second, the study focused on the motivation states experienced later in the lecture (i.e., while content was still being delivered, but towards the end of the session), so it did not include the motivation states that students may have experienced earlier in the lecture. These limitations should be considered when interpreting the findings.

There were also implications for future research. First, this study has revealed that even at university level many students can experience neutral and negative states of motivation. Very little is known about these phenomena. Yet they do warrant further study: At secondary levels of schooling for example, there are widespread concerns about the decline in student motivation in STEM-related subjects (Hagay \& Baram-Tsabari, 2015); and at tertiary level, roughly half the students who enroll in STEM disciplines drop out before finishing (Chen \& Soldner, 2013), so the extent to which neutral and negative motivation states might play a role in these issues should be investigated. Second, the study suggested that fatigue can negatively impact students' motivation states. Students reported that when too much information was packed into the lecture, they experienced fatigue to a point where they either stopped wanting to learn and/or had to try to force themselves to concentrate, and this was evident among STEM students in particular. It is known that fatigue can be caused by a range of factors, including sleep loss, prolonged periods of cognitive activity, and boredom (Baumeister, 2002; Boksem, Meijman, \& Lorist, 2005), but relatively little is known about the fatigue that can be caused by information overload during lectures, so this issue should be further investigated. In particular, it would be important to compare STEM and non-STEM lectures with regard to the pace at which new content is presented.

This has an important educational implication for STEM teaching at university level. It can be tempting for instructors to cram as much information as possible into their lectures, but this can result in some students "switching off" from learning. From that point on, the lecture is almost a waste of time for those students, as their concentration declines proportionally. In the present study, this problem appeared to be more widespread among STEM students. Given the challenges that many students already face in STEM studies it is important that students do not lose any opportunities to learn the content. Instructors in STEM disciplines should therefore ensure that new material is presented at a moderate pace that will allow all students to maintain positive motivation states until the lecture is completed.

\section{References}

1. M. Ainley (2006), Connecting with learning: Motivation, affect and cognition in interest processes. Educational Psychology Review, 18, 391-405. doi: 10.1007/s10648-006-9033-0

2. E. M. Anderman, S. M. Noar, R. S. Zimmerman, and L. Donohew (2004), The need for sensation as a prerequisite for motivation to engage in academic tasks. In P. R. Pintrich \& M. L. Maehr (Eds.), Advances in motivation and achievement, Volume 13, Motivating students, improving schools: The legacy of Carol Midgley (pp. 1-26). Boston, MA: Elsevier.

3. O. R. Anderson (1983), A neuromathematical model of human information processing and its application to science content acquisition. Journal of Research in Science Teaching, 20, 603-620.

4. R. F. Baumeister (2002), Ego depletion and self-control failure: An energy model of the self's executive function. Self and Identity, 1, 129-136.

5. Bayer Corporation (2014). The Bayer facts of science education XVI: US STEM workforce shortage - myth or reality? Fortune 1000 talent recruiters on the debate. Journal of Educational Technology, 23, 617-623.

6. M. A. S. Boksem, T. F. Meijman, and M. M. Lorist (2005), Effects of mental fatigue on attention: An ERP study. Cognitive Brain Research, 25, 107-116.

7. V. Braun and V. Clarke (2006), Using thematic analysis in psychology. Qualitative Research in Psychology, 3, $77-101$.

8. A. Byars-Winston (2014), Toward a framework for multicultural STEM-focused career interventions. Career Development Quarterly, 62, 340-357.

9. X. Chen and M. Soldner (2013), STEM attrition: College students' paths into and out of STEM fields. National Center for Educational Statistics, US Department of Education. 
10. J. G. Cromley, T. Perez, and A. Kaplan (2015), Undergraduate STEM achievement and retention: Cognitive, motivational, and institutional factors and solutions. Policy Insights from the Behavioral and Brain Sciences, 18 .

11. S. S. Culbertson, C. J. Fullagar, M. J. Simmons and M. Zhu (2015), Contagious flow: Antecedents and consequences of optimal experience in the classroom. Journal of Management Education, 39, 319-349. doi: $10.1177 / 1052562914545336$

12. N. B. Dohn (2013), Situational interest in engineering design activities. International Journal of Science Education, 35, 2057-2078.

13. N. Golafshani (2003), Understanding reliability and validity in qualitative research. The Qualitative Report, 8, 597-606.

14. E. Grossnickle (2016), Disentangling curiosity: Dimensionality, definitions, and distinctions from interest in educational contexts. Educational Psychology Review, 28, 23-60. doi: 10.1007/s10648-014-9294-y

15. J. Gyllenpalm (2018), Inquiry and flow in science education. Cultural Studies of Science Education, 13, 429-435. Doi: $10.1007 /$ s11422-016-9794-9

16. G. Hagay and A. Baram-Tsabari (2015), A strategy for incorporating students' interests into the high school science classroom. Journal of Research in Science Teaching, 52, 949-978.

17. H. Järvenoja, S. Järvelä and J. Malmberg (2017), Supporting groups' emotion and motivation regulation during collaborative learning. Learning and Instruction, Advance online publication. Retrieved from https://doi.org/10.1016/j.learninstruc.2017.11.004

18. T. Kim and D. L. Schallert (2014), Mediating effects of teacher enthusiasm and peer enthusiasm on students' interest in the college classroom. Contemporary Educational Psychology, 39, 134-144.

19. T. Long and M. Johnson (2000), Rigor, reliability, and validity in qualitative research. Clinical Effectiveness in Nursing, 4, 30-37.

20. A. Loukomies, K. Juuti and J. Lavonen (2015), Investigating situational interest in primary science lessons. International Journal of Science Education, 37, 3015-3037.

21. V. Maltese, C. S. Melki, and H. Wiebke (2014), The nature of experiences responsible for the generation and maintenance of interest in STEM. Science Education, 98, 937-962.

22. L. Menna-Barreto and D. Wey (2008), Time constraints in the school environment: What does a sleepy student tell us? Mind, Brain, and Education, 2, 24-28.

23. D. B. Miele and A. A. Scholer (2018), The role of metamotivational monitoring in motivation regulation. Educational Psychologist, 53, 1-21. doi: 10.1080/00461520.2017.1371601

24. K. A. Renninger and S. Hidi (2016), The power of interest for motivation and engagement. New York, NY: Routledge.

25. S. A. Rizvi (2015), RMP evaluations, course easiness, and grades: Are they related? Practical Assessment, Research 8 Evaluation, 20, 1-8.

26. J. I. Rotgans and H. K. Schmidt (2017), Interest development; Arousing situational interest affects the growth trajectory of individual interest. Contemporary Educational Psychology, 49, 175-184.

27. U. Schiefele (1999), Interest and learning from text. Scientific Studies of Reading, 3, 257-279.

28. J. L. Smith, K. L. Lewis, L. Hawthorne and S. D. Hodges (2013), When trying hard isn't natural: Women's belonging with and motivation for male-dominated STEM fields as a function of effort expenditure concerns. Personality and Social Psychology Bulletin, 39, 3-15.

29. M. Tekkumru-Kisa, M. K. Stein and C. Schunn (2015), A framework for analyzing cognitive demand and content-practices integration: Task analysis guide in science. Journal of Research in Science Teaching, 52, 659685.

30. D. B. Thoman, J. A. Arizaga, J. L. Smith, T. S. Story and G. Soncuya (2014), The grass is greener in nonscience, technology, engineering, and math classes: Examining the role of competing belonging to undergraduate women's vulnerability to being pulled away from science. Psychology of Women Quarterly, 38, 246-258.

31. Y. -M. Tsai, M. Kunter, O. Lüdtke, U. Trautwein and R. M. Ryan (2008), What makes lessons interesting? The role of situational factors and individual factors in three school subjects. Journal of Educational Psychology, 100, 460-472. doi: 10.1037/0022-0663.100.2.460

32. J. C. Turner and H. Patrick (2008), How does motivation develop and why does it change? Reframing motivation research. Educational Psychologist, 43, 119-131. doi: 10.1080/00461520802178441

33. M.-P. Vainikainen, H. Salmi and H. Thuneberg (2015), Situational interest and learning in a science center mathematics exhibition. Journal of Research in STEM Education, 1, 15-29. 
34. R. Vollmeyer and F. Rheinberg (2006), Motivational effects on self-regulated learning with different tasks. Educational Psychology Review, 18, 239-253. doi: 10.1007/s10648-006-9017-0

35. D. F. Whalen and M. C. Shelley II (2010), Academic success for STEM and non-STEM majors. Journal of STEM Education, 11, 45-60.

36. P. H. Winne and R. W. Marx (1989), A cognitive-processing analysis of motivation within classroom tasks. In C. Ames \& R. Ames (Eds.), Research on Motivation in Education, Volume 3, Goals and Cognitions (pp. 223-257). San Diego, CA: Academic Press.

37. A. Wolters (2003), Regulation of motivation: Evaluating an underemphasized aspect of self-regulated learning. Educational Psychologist, 38, 189-205.

38. A. Wolters and P. R. Pintrich (1998), Contextual differences in student motivation and self-regulated learning in mathematics, English, and social studies classrooms. Instructional Science, 26, 27-47. 